\title{
Performance Comparison of Stabilised Soils Based On their Liquefaction Resistances - A Review
}

\author{
Sandra Moncy, M.Tech Student, Saintgits College of Engineering, Kerala, India, \\ sandramoncy97@gmail.com \\ Hashifa Hassan P., Assistant Professor, Saintgits College of Engineering, Kerala, India, \\ hashifazamir@gmail.com
}

\begin{abstract}
The behavior of sands under undrained monotonic and cyclic loading are a widely discussed topic in fields of geotechnical engineering. The strength of cohesion less soils get drastically reduced under sudden undrained loading, especially if they are in saturated or submerged state, making them more prone to liquefaction. Researchers have conducted experiments on soils treated with a wide variety of chemicals, fibres,waste products and biopolymers to find out the liquefaction resistance of the modified sands. Among these additives, use of chemicals like cement pose major environmental problems like carbon dioxide emission and production of air pollutants like $\mathrm{SO}_{2}, \mathrm{NO}_{2}$, VOCs and other particulate matter. Plastic wastes such as PET bottles and plastic bags and byproducts like flyash and granulated blast furnace slag are used from past due to their strength enhancing properties. Plastic require thousands of years for their breakdown. The leachate generated by flyash and slag are slightly acidic in nature, polluting surface waters. Inorder to develop environment friendly construction practices, biopolymers like agar, starch, guar gel and xanthan gum are included recently in soil stabilization techniques. Being, renewable, reusable and carbon neutral, there is an increased interest on these biopolymers. This study is aimed at comparing the liquefaction resistances of modified and unmodified sands with a variety of additives based on results of Triaxial tests.
\end{abstract}

Keywords - Agar,biopolymers, monotonic loading, PET,soil stabilization,xanthan gum.

\section{INTRODUCTION}

The rapid build up of pore water pressure and reduction in effective confining stress will result in one of the most disastrous forms of geotechnical failure, liquefaction. Lack of proper drainage will result in pore pressure build up and hence undrained testing is commonly done to study liquefaction. Liquefaction occurs in the form of static liquefaction,blast liquefaction and dynamic liquefaction. Static liquefaction occurs when there is a sudden strength loss in a loose soil deposit when it is loaded and cannot drain. This form of liquefaction occurs very quickly and without any warning, but it is a rare event. A trigerring event such as vibrations from a construction equipment, stress increase due to a dam rise, loss of horizontal confining stress in a dam or foundation due to lateral strains are required for its occurrence.

The applicability of cementetious material like lime, Portland cement have been researched extensively since Industrial revolution and are found to the most popular stabilizing agents due to their pozzolanic reactions and cost effectiveness. The usage of cement is known to have detrimental environmental effects such as increasing the $\mathrm{pH}$ of soil to $12-13$ [13]. It is estimated that about $2 \%$ of total $\mathrm{CO}_{2}$ emissions is related to the usage of cement in geotechnical applications. The influence of fines such as bentonite on liquefaction resistance of sand is a debated topic as some studies show that addition of fines reduce the susceptibility of sand to liquefy while others suggested that strength get reduced with increase in fine content. Studies are also made in sands incorporated with lime or slag in addition to bentonite. The use of natural fibres such as coir, sisal, palm, jute, flax, wheat straw and so forth are inexpensive and provide significant reinforcement effects. Among all these, jute fibres have highest tensile strength. The increased use of lands for lanfilling and generation of greenhouse gases due to open burning of waste materials can be tackled by the using them in a well planned manner in civil engineering fields. Plastics like PET bottles and ceramics are also used in soil stabilization due to their elastoplastic properties and flyash and granulated blast furnace slag can be used for soil stabilization alone or in combination with other chemical or polymer additives. There also arises problems like leachate generation,surface water pollution and soil pollution. The development of green technologies have garnered attention due to the 
growing concerns on climate change and global waming. Biopolymers like agar, starch, guar gel and xanthan gum are gaining attention of researchers due to their biodegradation characteristics. These are hydrocarbon polymers produced from microbial systems such as bacteria, fungi or algae, or from higher organisms such as plants and are considered as a greenhouse gas reduction strategy since their contribution to global climate change is only $2 \mathrm{~kg}$ of $\mathrm{CO}_{2}$ equivalent per $\mathrm{kg}$ of biopolymer whereas petroleum based polymers like Nylon 66 or Nylon 6 produce 7 to $8 \mathrm{~kg}$ of $\mathrm{CO}_{2}$ equivalent per $\mathrm{kg}$ of polymer.

The influence of chemicals, fibres, waste products and biopolymers upon liquefaction resistance of sands based on Triaxial test results have been discussed in this paper. The increase in strength of modified sands with respect to the untrated sands are expressed in terms of strength ratio, while the reduction in undrained shear strength is evaluated on the basis of brittleness index.

\section{LIQUEFACTION MITIGATION IN SANDS USING NATURAL AND SYNTHETIC MATERIALS}

\section{A. Incorporation of chemical additives}

Hasanlourad et al, 2018 [7] studied the influence of bentonite in improving shear strength properties by conducting consolidated undrained triaxial tests on $38 \mathrm{~mm} \mathrm{x}$ $76 \mathrm{~mm}$ Firoozkooh sand samples by adding $0 \%, 5 \%$ and $10 \%$ at $30 \%$ and $80 \%$ relative densities at confining pressures of $100,200,300$ and $400 \mathrm{kPa}$. The samples showed an increasing pattern for deviator stress and thereafter it remained almost constant. A peak deviator stress of 1900 $\mathrm{kPa}$ at a confining pressure of $300 \mathrm{kPa}$ was shown by the untreated dense sand sample at an axial strain of $7.5 \%$.The results also indicated that maximum deviator stress decreased with increase in bentonite content initially and thereafter it increased for majority of samples. From the graph, optimum dosage of bentonite can be selected as between $5 \%$ and $10 \%$. The maximum deviator stress values were $1870 \mathrm{kPa}$ and $1695 \mathrm{kPa}$ at $10 \%$ and $5 \%$ bentonite at $300 \mathrm{kPa}$ confining pressures repectively. It can be seen that the peak deviator stress at failure was more for the untreated sand. Pore water pressure showed an increasing trend initially, then it started to decrease. While considering excess pore pressure at $200 \mathrm{kPa}$ confining pressure of loose samples, $125 \mathrm{kPa}$ was the maximum value shown by sand with $10 \%$ bentonite, while at $5 \%$ bentonite content, the pore pressure was only $100 \mathrm{kPa}$. A negative excess pore pressure of $200 \mathrm{kPa}$ was shown by the untreated sand .The strength factor which is the ratio of peak deviator stress of modified sand to unmodified sand is calculated as 1 .

The dosage of bentonite is an important parameter in determining the liquefaction susceptibility of sandbentonite mixture. Sand mixed with $\leq 4 \%$ bentonite resulted in rapid liquefaction of sand due to generation of excess pore pressure while $5-14 \%$ bentonite made sand more resistant to liquefaction due to the complete coating of sand by bentonite [4]. So, chemicals such as slag, lime, flyash and granulated blast furnace slag are generally added to sand bentonite mixtures to overcome these limitations.

Keramatikerman et al, 2018 [4] evaluated the effects of incorporation of lime on static liquefaction resistance of sand bentonite mixtures. A series of triaxial tests were conducted to study the influence of $0 \%$ and $10 \%$ bentonite and $0 \%, 3 \%, 5 \%$ and $7 \%$ lime at relative densities of 10, 20 and $30 \%$ at an effective confining stress of $150 \mathrm{kPa}$. While considering deviator stress values, it can be seen that it incrased with increase in confining pressures and relative density. The maximum deviator stresse of unmodified soil was $103 \mathrm{kPa}$ at $0.5 \%$ axial strain and that of sand containing $10 \%$ bentonite and $7 \%$ lime was $229 \mathrm{kPa}$ at $2 \%$ axial strain. At $10 \%$ relative density, a maximum value of $145 \mathrm{kPa}$ and a minimum of $60 \mathrm{kPa}$ was shown for excess pore water pressure by untreated soil and sand bentonite mixtures with $7 \%$ lime respectively at $5 \%$ and $0.5 \%$ axial strains .The strength factor was calculated as 3 . The stabilizers will be effective when they are used as $10 \%$ bentonite and $7 \%$ lime.

\section{B. Incorporation of Fibres}

The major drawback of cemented sand is their brittle behaviour,which can be avoided by incorporating random, discrete fibres.

Malidarreh et al, 2017 [8] conducted triaxial tests on cement treated Babolsar sand mixed with $0.5 \%$ and $1 \%$ of sacks, PET Fibre and PP fibre at three confining pressures, $50 \mathrm{kPa}, 100 \mathrm{kPa}$ and $200 \mathrm{kPa}$. The samples of $38 \mathrm{~mm}$ diameter and $76 \mathrm{~mm}$ height were prepared at a relative density of $70 \%$. At a confining pressure of $200 \mathrm{kPa}$, untreated soil showed a peak deviator stress of $1250 \mathrm{kPa}$ at an axial strain of $2.5 \%$ while sand treated with $1 \%$ PP fibres and $1 \%$ PET showed maximum stresses of $2400 \mathrm{kPa}$ at an axial strain of $6 \%$ and $2300 \mathrm{kP}$ at $7 \%$ axial strain respectively. After analyzing the results, it was seen that the peak strength and strain at failure increased with the addition of fibres to the cemented sand. It can be concluded that an optimum dosage of $1 \%$ PP fibres can increase the strength of ordinary sand to two times its original strength and hence, it proves to be more effective than sack and PET fibres.

The reinforcing effect of fibre depends on fibre properties such as fibre length, type, content, modulus of elasticity, etc, soil properties such as particle size, shape and gradation, and preparation parameters like water content and dry density. Fibres impart shear strength, tensile strength, compressive strength, liquefaction resistance, bearing capacity to soil and reduces the swelling tendancy of expansive soils and brittleness [14]. 
Lal et al, 2017 [5] evaluated the effectiveness of coir as a reinforcement material by conducting undrained triaxial tests on river sand incorporated with three different forms of coir such as geocell, planar and discrete forms. The tests were conducted at three different confining pressures, i.e, 100,200 and $300 \mathrm{kPa}$. The values of maximum and minimum deviator stresses at different confining pressures and corresponding axial strains at failure of reinforced and unreinforced sands were compared. Unreinforced sand showed a maximum deviator stress of and $1552 \mathrm{kPa}$ at an axial strain of $19 \%$. When peak deviator stresses of reinforced sands were analysed, sand with geocell coir form showed a maximum value of $1982 \mathrm{kPa}$ while sand with planar coir showed a peak value of $2561 \mathrm{kPa}$.The trend of pore water pressure variation was similar to that observed in previous cases,i.e, first it increased along with axial strains, then it starts to decrease at higher strains. Peak pore water pressure shown by unreinforced sand was $170 \mathrm{kPa}$ and by discrete, geocell and planar reinforced sands were 179,183 and $197 \mathrm{kPa}$ respectively. It was also seen that the provision of coir reinforcement as geocell improved the strength factor approximately to 2. Eventhough planar showed a greater deviatoric stress than geocell, geocell showed very high deviator stress values with its small tensile strength of $1.04 \mathrm{kN} / \mathrm{m}$ ( $6.5 \%$ of parent geotextile material). Also,the pore pressure value shown by the sand with geocell was lower than that containing planar form of coir.

\section{Incorporation of Waste materials}

Salimi et al, 2019 [10] used plastic sheets obtained from melting of waste water bottles as a stabilizing agent to effectively reduce the problems associated with waste disposal. Cylindrical sand samples of $50 \mathrm{~mm}$ diameter and $100 \mathrm{~mm}$ height were prepared by incorporating $0,1,2$ and 3 plastic sheet layers of $0.4 \mathrm{~mm}$ thickness. Triaxial tests were conducted on these samples at $70 \%$ relative density and at confining pressures of 50, 100 and $200 \mathrm{kPa}$. From the deviator stress vs axial strain graph, it can be seen that sand reinforced with 3 layers of plastic sheets showed maximum deviator stresses, say, $1800 \mathrm{kPa}$ at $11 \%$ of axial strain. A peak value of $600 \mathrm{kPa}$ was shown by the unreinforced sand at $3 \%$ of axial strain, when tested at $200 \mathrm{kPa}$ confining pressure. The strength ratio vs confining pressure graph clearly suggests that sand reinforced with three layer of plastic sheets showed a strength improvement of about 4 times. It can be concluded that three layers of plastic sheets is necessary to get the desirable properties in plain sand.

Sabbar et al, 2017 [11] conducted triaxial tests on 50mm diameter and $100 \mathrm{~mm}$ high specimens of Perth sand and sand modified with 2, 4 and $6 \%$ of granulated blast furnace slag, subjected to a confining pressure of $100 \mathrm{kPa}$ at $80 \%$ relative density. From deviator stress vs axial strain graph, it can be seen that deviator stresses are increasing as the dosage of slag was increased from 4 to $6 \%$. Untreated sand and sand with $6 \%$ slag showed peak deviator stresses of 100 $\mathrm{kPa}$ and $170 \mathrm{kPa}$ respectively at an approximate axial strain of $4 \%$. Here, the strength factor is 1.5. Slag dosage in between 4 to $6 \%$, i.e, $5 \%$ can be considered optimum.

Sabbar et al, 2017 [12] studied the phenomenon of static liquefaction in clean perth sand,sand with $3 \%$ bentonite, sand with $2 \%, 4 \%$ and $6 \%$ slag and sand containing $3 \%$ bentonite and slag at 2, 4 and $6 \%$. Triaxial tests were conducted on specimens of $50 \mathrm{~mm}$ diameter and $100 \mathrm{~mm}$ height in undrained conditions at very low relative densities (10\% and 20\%) at confining pressures of 100, 150 and 200 $\mathrm{kPa}$. The maximum deviator stress values shown by untreated sand and sand with $3 \%$ bentonite and $4 \%$ slag were $7 \mathrm{kPa}$ and $38.6 \mathrm{kPa}$ at $100 \mathrm{kPa}$ confining pressure respectively. While analyzing excess pore pressure, $160 \mathrm{kPa}$ was shown by untreated sand and the modified sand showed only $92 \mathrm{kPa}$. A strength factor of 5 was obtained when the samples were incorporated with $3 \%$ bentonite and $4 \%$ slag.

Lal et al, 2018 [1] made an attempt to study the behavior of sand modified with combination of blast furnace slag and plastic reinforcement. Triaxial tests were performed on 38 $\mathrm{mm}$ diameter and $76 \mathrm{~mm}$ height sand-slag mixtures, with and without plastic reinforcement at 100, 200 and $300 \mathrm{kPa}$ confining pressures. $2 \mathrm{~mm}$ wide plastic strips were added at mix ratios of 1,2 and $3 \%$. From the obtained results, it was seen that 1200,1240 and $1280 \mathrm{kPa}$ were the maximum deviator stresses at $1,2,3 \%$ mix ratios respectively for a confining pressure of $300 \mathrm{kPa}$. The minimum deviator stress values of 680,700 and $740 \mathrm{kPa}$ were shown at a confining pressure of $100 \mathrm{kPa}$, corresponding to mix ratios of $1,2,3 \%$ respectively. It can be seen that the deviator stress and the corresponding axial strain values increased with increase in mix ratios and cell pressures. Here, the optimum mix ratio can be taken as $3 \%$ with respect to weight of blast furnace slag.

Keramatikerman et al, 2018 [3] analysed the liquefaction resistance of Perth sand modified by $5 \%$ bentonite and 3, 5, $7 \%$ flyash by conducting undrained triaxial tests on 62.5 $\mathrm{mm}$ diameter and $125 \mathrm{~mm}$ height specimens. The specimens prepared at relative densities of 10, 20 and $30 \%$ were tested under a confining pressure of $100 \mathrm{kPa}$. The results clearly indicate that the deviator stress is increasing with increase in flyash content. A peak deviator stress of $300 \mathrm{kPa}$ was shown by sand- bentonite mixture with $7 \%$ flyash and the corresponding axial strain was $20 \%$ at $30 \%$ relative density. On the other hand, untreated soil showed a value of only $167 \mathrm{kPa}$ around same axial strain. A maximum pore pressure of $100 \mathrm{kPa}$ was shown by untreated soil and a value of $40 \mathrm{kPa}$ was shown by SB mixture with $7 \%$ flyash content at lower density. It can be concluded that addition of flyash to sand bentonite mixture has the ability to increase the strength to three times the initial value and $7 \%$ 
flyash in $5 \%$ bentonite sand mixture performs well in liquefaction mitigation.

\section{Incorporation of Biopolymers}

The past researches have shown that biopolymers can be used in soil erosion control and slope protection, prevention of slope failure, improve slope stability reduction of water infiltration into slopes. The experiments conducted on soils treated with biopolymers suggest that they can increase the unconfined compressive strength, shear strength, cohesion, stiffness and reduce permeability.

Smitha et al, 2019 [13] investigated the efficiency of agar biopolymers in improving the undrained shear strength of silty sands on $50 \mathrm{~mm}$ diameter samples, both treated and untreated. The samples containing $0.5,1$ and $2 \%$ of agar in silty sand at a relative density of $30 \%$ were subjected to confining pressures of $50 \mathrm{kPa}, 100 \mathrm{kPa}$ and $150 \mathrm{kPa}$ in triaxial test. Untreated soil showed a pesk deviator stress of $209 \mathrm{kPa}$ while 28 days cured specimen with $2 \%$ agar showed a peak deviator stress of $308 \mathrm{kPa}$ at a confining pressure of $150 \mathrm{kPa}$. But the values of deviator stress obtained for uncured, modified specimens were lower than the values obtained for untreated specimens. It can be concluded that $2 \%$ of agar would result in improved properties of soil and deviator stress increase with increase in agar dosage and curing time. Agar has the ability to increase the strength of virgin sample to 2 .

Lee et al, 2019 [6] incorporated $0.5 \%, 1 \%$ and $2 \%$ of a gel type biopolymer, xanthan gum into Sydney sand and conducted triaxial tests on the samples at confining pressures of 50, 100 and $200 \mathrm{kPa}$. The gel was incorporated in sand in both hydrated and dehydrated conditions to check the sensitivity of biopolymers to water. In the case of untreated soil, deviatoric stress increased from $250 \mathrm{kPa}$ to $920 \mathrm{kPa}$ when the confining pressure was increased from 100 to $200 \mathrm{kPa}$. The values of deviator stress when the biopolymer was in hydrated state was very much lower than that of untreated sand. On the other hand, in dehydrated condition the values of ultimate deviator stresses were $313 \%$ more than the untreated sample and $513 \%$ more than the sample with gel in hydrated condition. It can be seen that xanthan gum functions effectively in improving the properties of sand when it is in dry state and a dosage of $2 \%$ can be treated as optimum. Strength of sand can be enhanced to about thirteen times when xanthan gum is used in dry state.

Table 2a Triaxial test results of dense modified sand
Khatami et al, 2013 [9] made experimental investigations on $38 \mathrm{~mm}$ diameter and $76 \mathrm{~mm}$ long samples prepared by mixing Fontainebleau sand with 1, 2 and $4 \%$ microbiological grade agar with six modified starch (Staramic 105 and 747and Starpol 136, 469, 600 and 700 ) at $0.5-1 \%$ dosages. Triaxial tests were conducted at 100 , 200 and $400 \mathrm{kPa}$ confining stresses. The test results indicated that $1 \%$ agar grout as the main component and $1 \%$ Starpol 136 or $0.5 \%$ of Starpol 600 in sand had almost the same effect. At a confining stress of $400 \mathrm{kPa}$, a peak deviator stress of $1100 \mathrm{kPa}$ was shown by sand treated with $4 \%$ agar along with $1 \%$ of Starpol 136 and $0.5 \%$ of Starpol 600 in combination with $1 \%$ agar had almost the same effect i.e, peak deviator stress of approximately $1000 \mathrm{kPa}$ was obtained in both cases at a confining pressure of 400 $\mathrm{kPa}$. In this case $1 \%$ agar grout as the main component and $1 \%$ Starpol 136 or $0.5 \%$ of Starpol 600 as additive can be considered as an effective combination. Strength ratio can be calculated as 2.5 at $400 \mathrm{kPa}$ confining pressure.

\section{DISCUSSIONS}

The values of parameters like Maximum deviator stress, axial strain at failure, excess pore pressure, strength factor and brittleness index of the modified sands at optimum additive dosages based on triaxial test are analysed and recorded in Table 2 and 3. Based on these values graphs were also plotted.The results are divided into two parts, based on the relative density at which the tests are made.

Table 1 . Classification of soil based on relative density (\%)

\begin{tabular}{|c|c|}
\hline Relative density $(\%)$ & State of compaction \\
\hline $0-15$ & Very loose \\
\hline $35-65$ & Loose \\
\hline $65-85$ & Medium dense \\
\hline $85-100$ & Dense \\
\hline $85-100$ & Very dense \\
\hline
\end{tabular}

\begin{tabular}{|c|c|c|c|c|c|c|c|c|c|c|c|c|c|}
\hline Materials & Ber & tonite & $5 \%)$ & $\mathrm{Pla}$ & fibre ( & PP) & & $\operatorname{ir}(\mathrm{Ge}$ & & Recycl & $\begin{array}{c}\text { ste pla } \\
\text { nos) }\end{array}$ & sheets (3 & Slag (4\%) \\
\hline $\begin{array}{l}\text { Confining stress } \\
(\mathrm{kPa})\end{array}$ & 100 & 200 & 300 & 50 & 100 & 200 & 100 & 200 & 300 & 50 & 100 & 200 & 100 \\
\hline $\begin{array}{l}\text { Maximum deviator } \\
\text { stress }(\mathrm{kPa})\end{array}$ & 1100 & 1470 & 1695 & - & 1700 & 2400 & 1102 & 1439 & 1982 & 850 & 1300 & 1800 & 148 \\
\hline
\end{tabular}




\begin{tabular}{|l|c|c|c|c|c|c|c|c|c|c|c|c|c|}
\hline Axial strain(\%) & - & 20 & - & - & 6 & 6 & 24 & - & - & 8 & 10 & 11 & 4 \\
\hline $\begin{array}{l}\text { Maximum Excess } \\
\text { pore pressure (kPa) }\end{array}$ & - & 50 & & - & - & - & 183 & - & - & - & - & - & - \\
\hline Axial strain(\%) & - & 2 & & - & - & - & 1 & - & - & - & - & - & - \\
\hline Strength factor & 1 & 1 & 1 & - & - & 2 & 2 & 2 & 1 & 4 & 4 & 3 & 1.5 \\
\hline Brittleness index,IB & - & 0.06 & - & 0.48 & 0.28 & 0.20 & - & - & - & 0.32 & 0.08 & 0.055 & 0.12 \\
\hline
\end{tabular}

Table $2 b$ Triaxial test results of dense modified sand

\begin{tabular}{|c|c|c|c|c|c|c|c|c|c|}
\hline Materials & \multicolumn{3}{|c|}{ Agar(1\%)+ Starpol $136(1 \%)$} & \multicolumn{3}{|c|}{ Dehydrated xanthan gum (2\%) } & \multicolumn{3}{|c|}{$\begin{array}{l}\text { Blast furnace slag + } \\
\text { recycled plastic }(3 \%)\end{array}$} \\
\hline Confining stress $(\mathrm{kPa})$ & 100 & 200 & 400 & 50 & 100 & 200 & 100 & 200 & 300 \\
\hline $\begin{array}{l}\text { Maximum deviator } \\
\text { stress }(\mathrm{kPa})\end{array}$ & 750 & 850 & 1100 & 3300 & 3350 & 3800 & 740 & 960 & 1280 \\
\hline Axial strain (\%) & 2.1 & 2.7 & 9 & 3.2 & 1.5 & 3.8 & 6 & 7 & 8 \\
\hline Strength factor & 2.5 & 2 & 1.5 & 13 & 8 & 4 & - & - & - \\
\hline Brittleness index, $\mathrm{I}_{\mathrm{B}}$ & - & - & - & 0.95 & 0.69 & 0.65 & 0.2 & 0.2 & 0.22 \\
\hline
\end{tabular}

Table 3 Triaxial test results of loose modified sand

\begin{tabular}{|c|c|c|c|c|c|c|c|c|c|c|c|}
\hline Materials & \multicolumn{3}{|c|}{ Bentonite (5\%) } & $\begin{array}{c}\text { Lime (7\%) } \\
+ \\
\text { Bentonite } \\
(4 \%)\end{array}$ & \multicolumn{3}{|c|}{$\begin{array}{c}\text { Slag }(4 \%) \\
+ \\
\text { Bentonite } \\
(3 \%)\end{array}$} & $\begin{array}{c}\text { Flyash (7\%) } \\
+ \\
\text { Bentonite } \quad(5 \%)\end{array}$ & \multicolumn{3}{|c|}{ Agar (2\%) } \\
\hline Confiningstress (kPa) & 100 & 200 & 300 & 150 & 100 & 150 & 200 & 100 & 50 & 100 & 150 \\
\hline $\begin{array}{l}\text { Maximum deviatoric } \\
\text { stress }(\mathrm{kPa})\end{array}$ & 1010 & 1148 & 1485 & 229 & 38.6 & 31 & 38 & 300 & 145 & 242 & 308 \\
\hline Axial strain (\%) & - & 20 & - & 2 & 23 & - & $-\frac{1}{10}+a+0$ & 20 & & - & - \\
\hline $\begin{array}{l}\text { Maximum excess } \\
\text { pore pressure }(\mathrm{kPa})\end{array}$ & - & 100 & & 80 & 33 & 51 & 92 & 38 & - & - & - \\
\hline Axial strain $(\%)$ & - & 2.5 & - & 2.5 & 1 & $=0$ & - & 4 & & - & - \\
\hline Strength factor & 1 & 1 & 1 & 3 कh & Engine 5 & 3 & 2 & 3 & 2 & 2 & 1.5 \\
\hline Brittleness index & - & 0 & - & 0.007 & 0.01 & - & - & 0.02 & - & - & - \\
\hline
\end{tabular}

\section{A. Variation of Maximum deviator stress of the} modified soils with relative density

The value of maximum deviator stress is the deviator stress shown by the modified soil at failure during Triaxial test. Usually, the value of deviator stress increases with relative density and confining pressures, while a behavior different from this was seen in few cases. After comparing these maximum deviator stress values as in figures 1 and 2, it was observed that the higher value was shown by the dense mixes. Xanthan gum modified soil when prepared at higher density showed $156 \%$ more deviator stress value than the loose bentonite modified soil.The least value was shown by the soil containing slag and bentonite in combination (38 $\mathrm{kPa}$ ) in loose condition, while sand incorporated with slag alone resulted in a peak deviator stress of $148 \mathrm{kPa}$ in dense state.Hence, it can be concluded that the modified soil with greater deviator stress at failure is better in resisting liquefaction. 


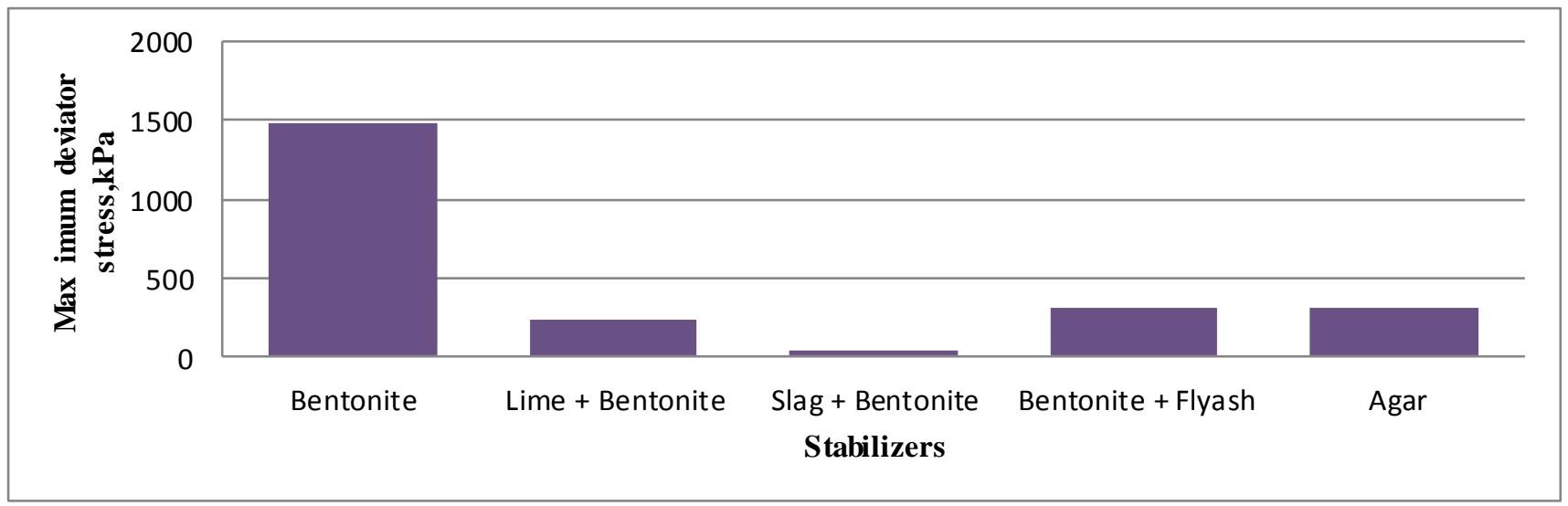

Fig 1 Plot of Maximum deviator stress vs stabilizers for loose mixes at optimum content

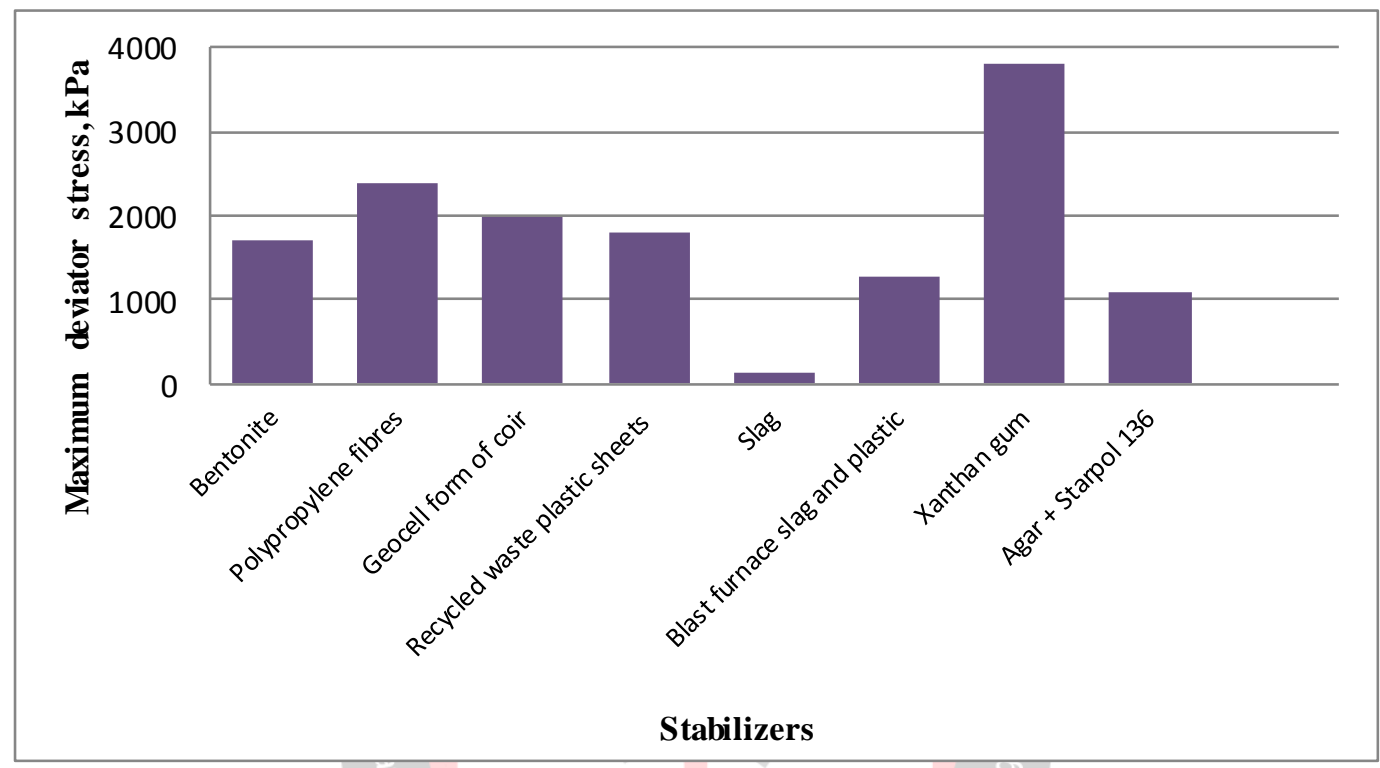

Fig 2 Plot of Maximum deviator stress vs stabilizers for dense mixes at optimum content

\section{B. Variation of Maximum Deviator stress of the modified soils with Confining Pressures}

The graphs 3 and 4 clearly indicates that the deviator stress values are increasing with increase in confining pressures, for both loose and dense mixes, except in case of slag and bentonite incorporated in combination in sand.This trend of increase in deviator stress with increase in confining stress is favourable since the loose samples get densified with increase in confining stresses, thereby reducing the compressibility of the sample and resulting in a stable fabric. While comparing deviator stress values of bentonite incorporated sand in loose state, maximum deviator stress value increased from $1010 \mathrm{kPa}$ to $1485 \mathrm{kPa}$ as the confining stress was increased from $100 \mathrm{kPa}$ to $300 \mathrm{kPa}$. When deviator stresses of sand with xanthan gum were compared, they also showed a similar trend i.e, deviator stress increased from $3300 \mathrm{kPa}$ to $3800 \mathrm{kPa}$ as confining stress was increased from 50 to $200 \mathrm{kPa}$. Hence, it can be concluded that the confining stress at which the Triaxial test is made is also significant in analyzing the liquefaction susceptibility soils. 


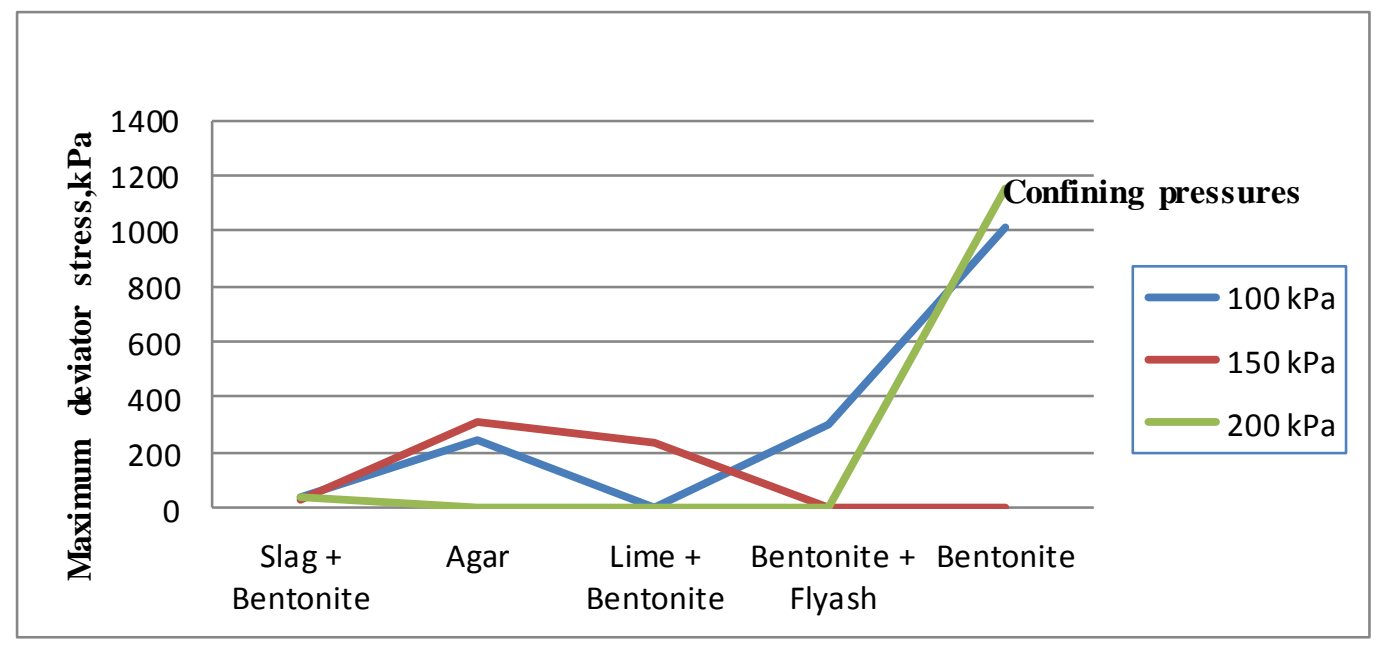

Fig 3 Plot of Maximum deviator stress vs stabilizers at varying confining pressures for loose mixes at optimum content

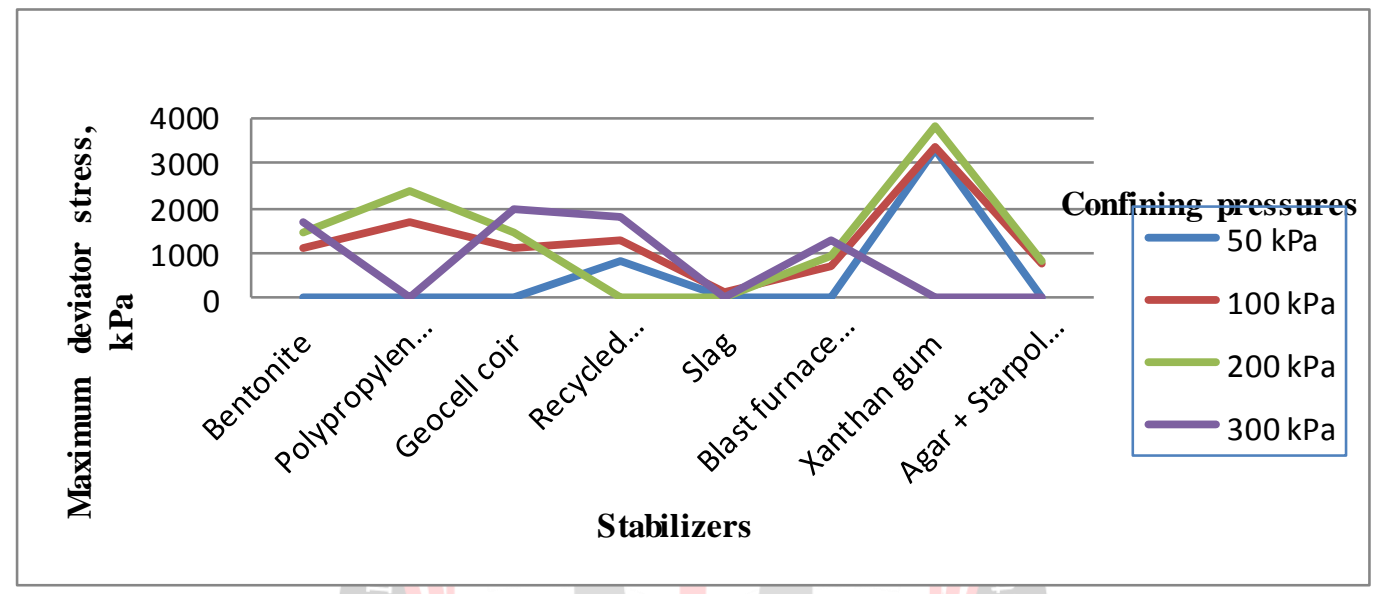

Fig 4 Plot of Maximum deviator stress vs stabilizers at varying confining pressures for dense mixes at optimum content

\section{Influence of stabilizers on Excess pore pressure at}

\section{varying confining pressures}

When saturated soils are subjected to undrained loading, a rapid build up of pore water pressure occurs, causing reduction in strength and ultimately liquefaction/ of soils.From the graph 5, it can be seen that when coir was incorporated in the form of geocell in sand, excess pore pressure was maximum and the minimum pore pressure was shown by sand containing slag and bentonite in combination at a confining stress of $100 \mathrm{kPa}$. This trend can be attributed to the ability of slag to reduce the interparticle bonds and hence the pore water pressure.

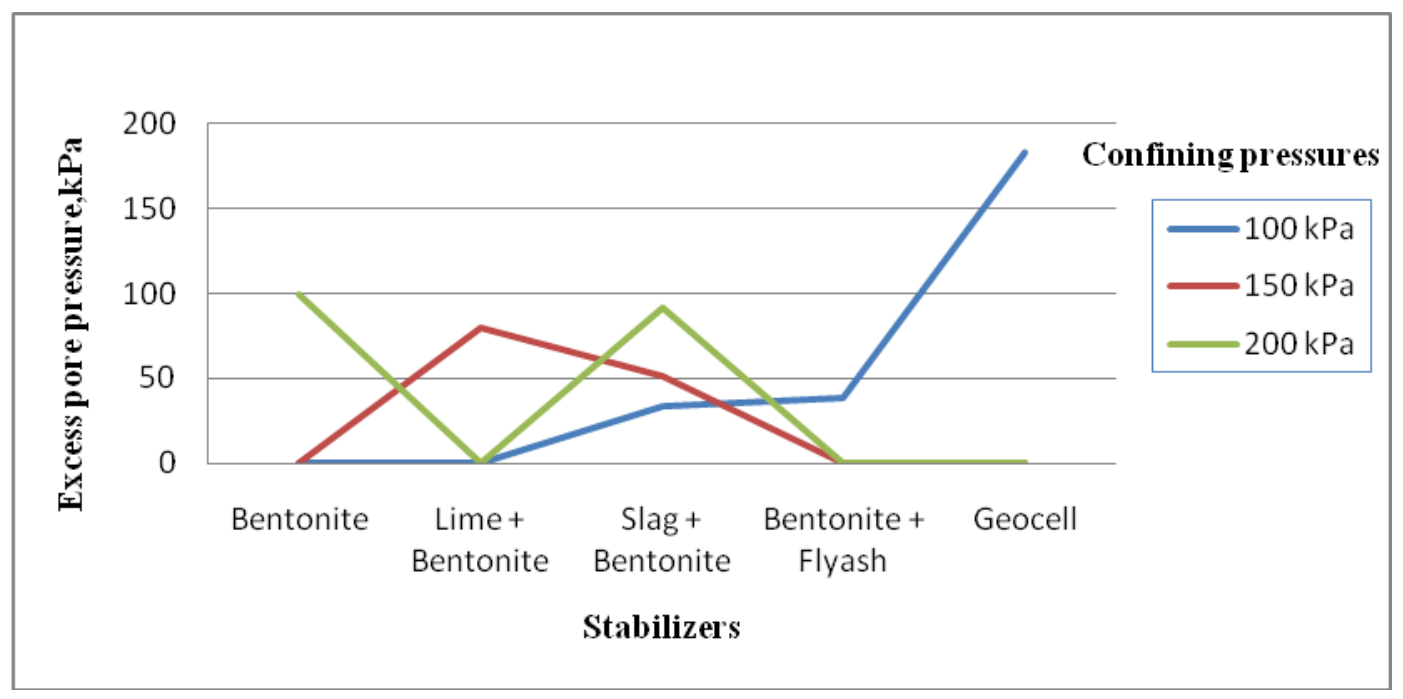

Fig 5 Plot of Excess pore pressure vs stabilizing agents at varying confining pressures 


\section{Influence of stabilizers on strength factor at varying}

Strength factor or strength ratio gives us an idea about the improvement in strength of the modified sand with respect to the unmodified sand. From the graphs 6 and 7, it can be seen that Xanthan gum has the ability to increase the strength of sand to thirteen times while bentonite is not very

\section{confining pressures}

efficient in increasing the strength. But when slag was used in bentonite incorporated sand, the strength was increased to five times the initial value.

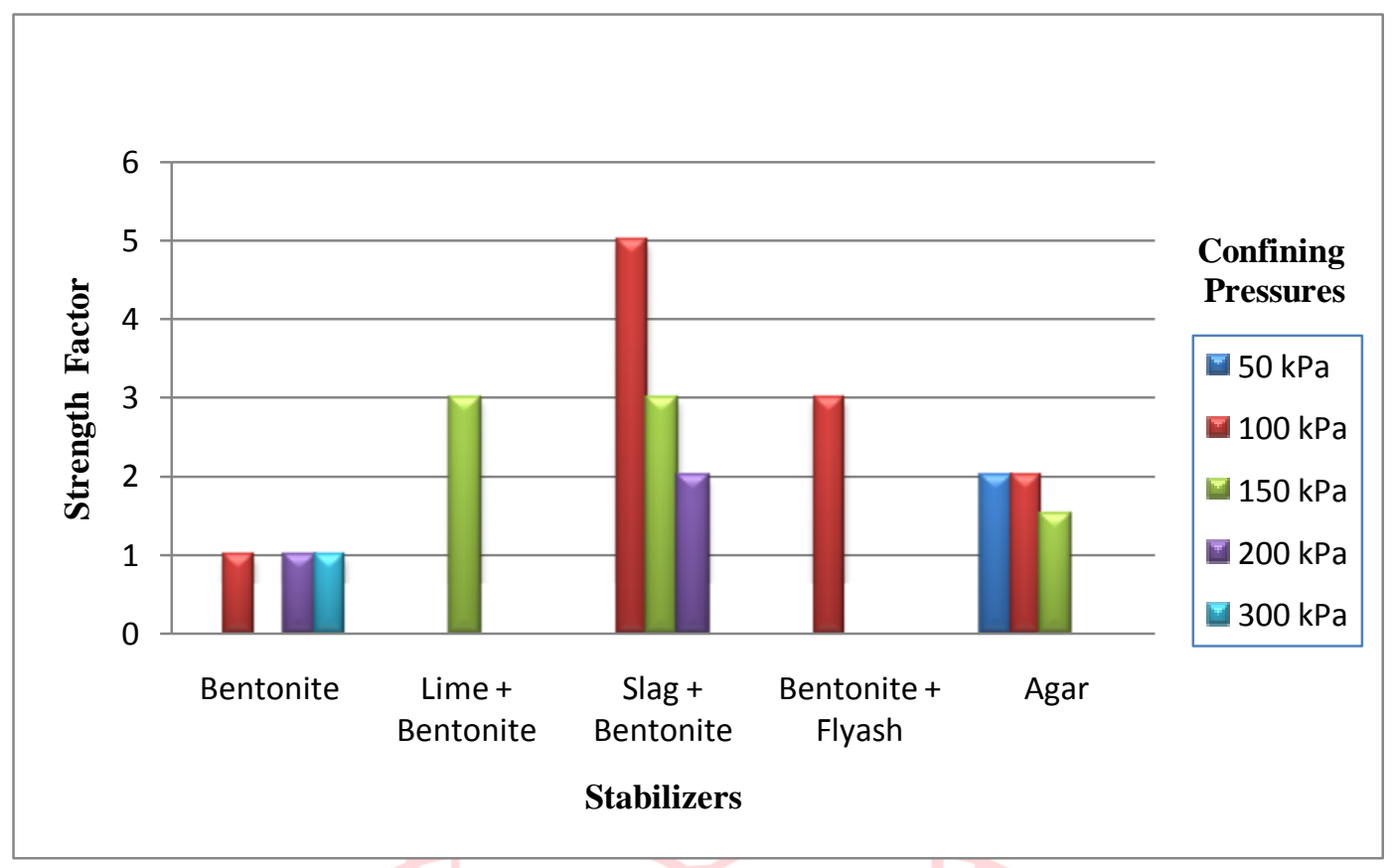

Fig 6 Plot of Strength factor vs stabilizers at varying confining pressures for loose mixes at optimum content

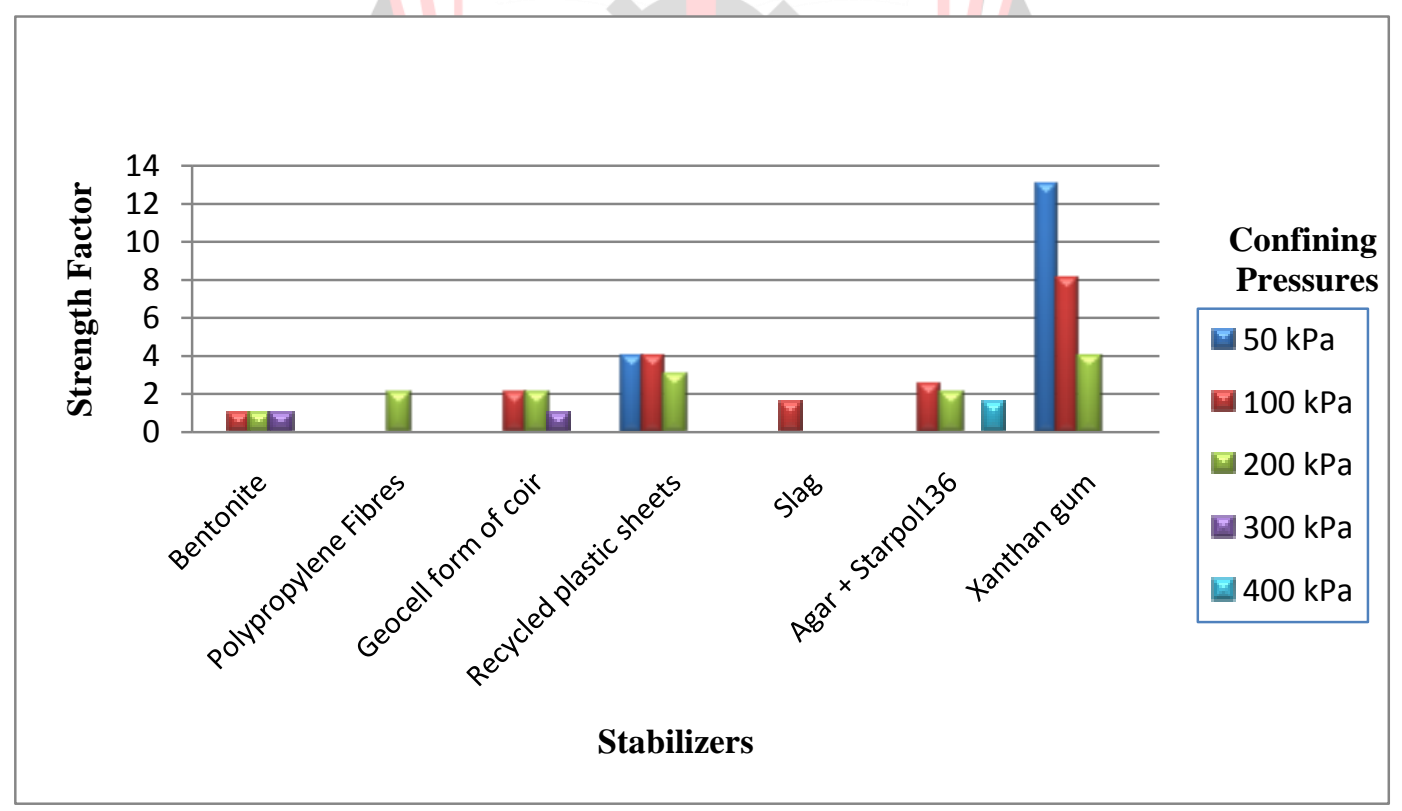

Fig 7 Plot of Strength factor vs stabilizers at varying confining pressures for dense mixes at optimum content

\section{E. Effect of stabilizers on liquefaction of sands}

The reduction in undrained shear strength that occurs during liquefaction is expressed in terms of brittleness index, $I_{B}$ and the value ranges from 0 to $1 . \mathrm{I}_{\mathrm{B}}$ value of 1 indicates a brittle behavior whereas a value of 0 indicates non brittle behavior.A maximum value for brittleness index was shown by xanthan gum and minimum by sand containing lime and bentonite together.However, the values of brittleness index for the stabilized soils as from figures 8 and 9 , were less than one, indicating non brittle or non flow behavior. 


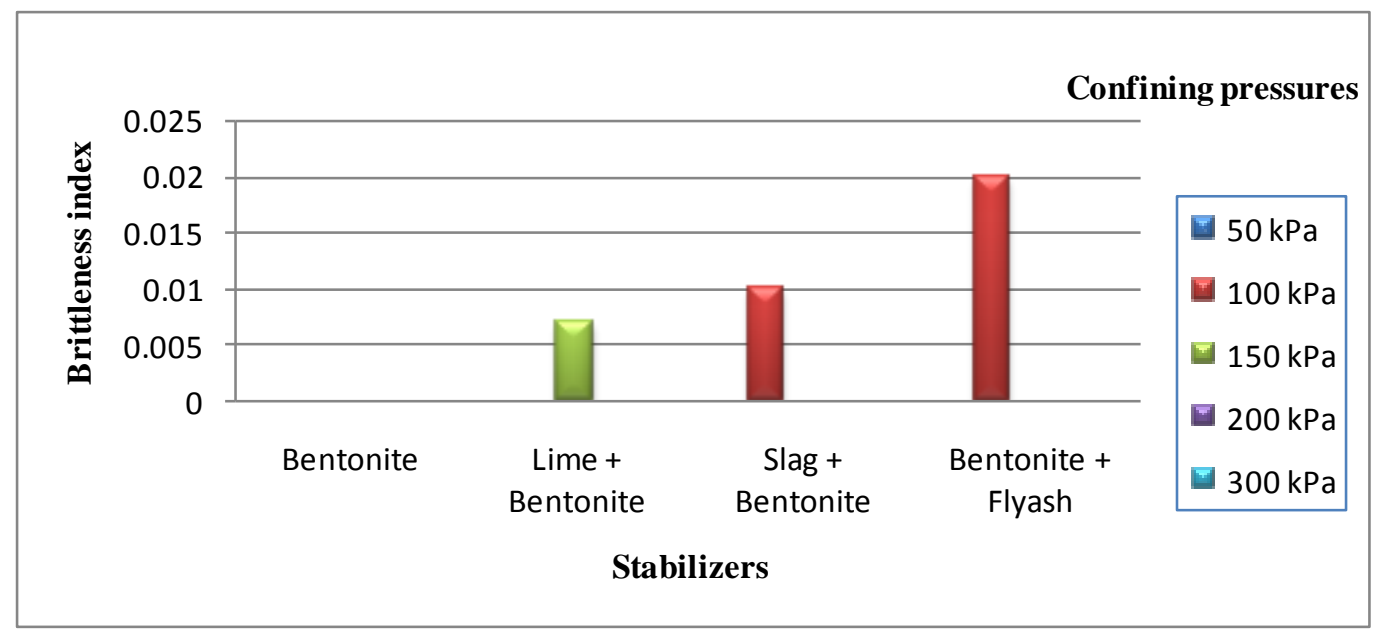

Fig 8 Plot of Brittleness index vs stabilizers at varying confining pressures for loose mixes at optimum content

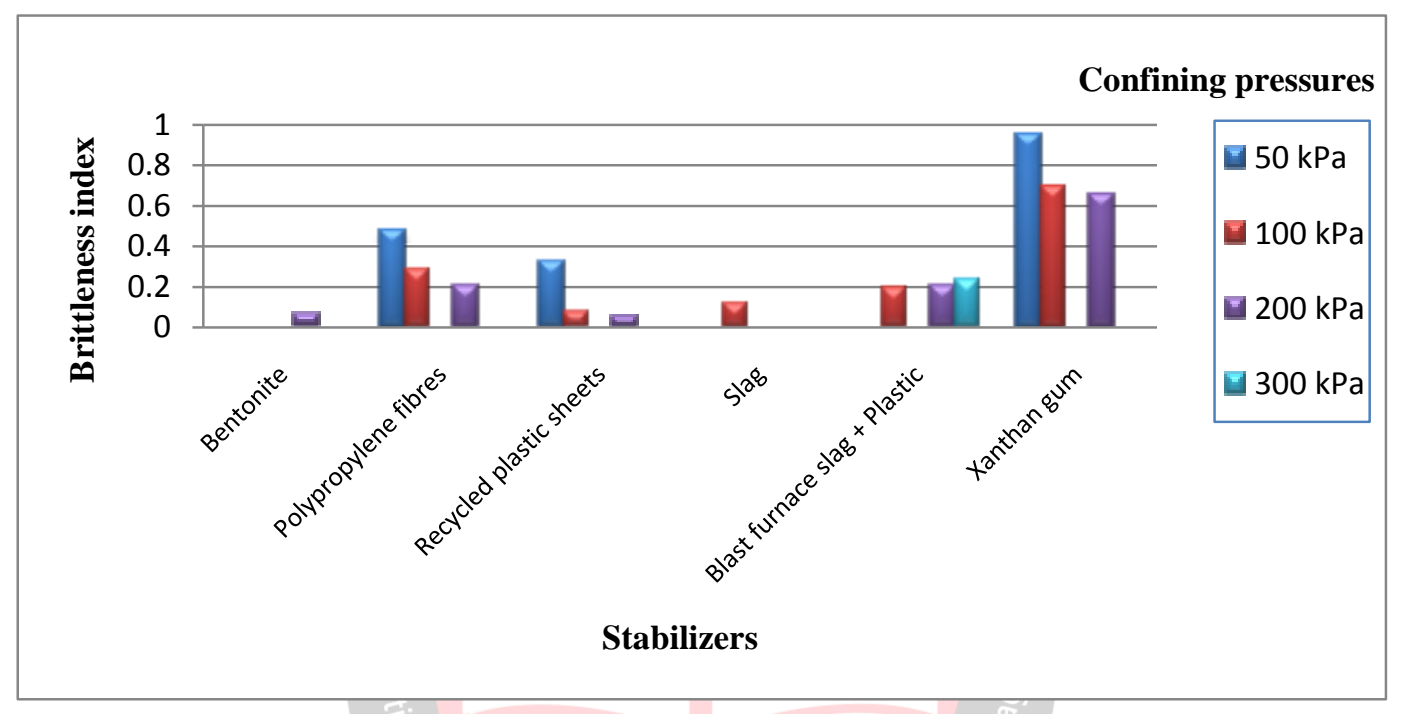

Fig 9 Plot of Brittleness index vs stabilizers at varying confining pressures for dense mixes at optimum content

\section{CONCLUSIONS}

The important conclusions made after reviewing experimental studies on treated and untreated sands based on Triaxial tests are as follows:

1) The influence of chemicals, fibres, waste products and biopolymer additives on liquefaction resistance of sandy soils have been studied extensively.

2) Liquefaction resistance of the modified sands are expressed in terms of maximum deviator stress, excess pore water pressure, strength factor and brittleness index.

3) It was seen that deviator stress and the corresponding axial strain increased with increase in confining pressure, relative density and percentage of additive, except a few.

4) After comparing maximum deviator stress values, it was seen that at lower relative density, bentonite incorporated sand showed the maximum value of $1148 \mathrm{kPa}$ but the value shown by untreated sand was $0.2 \%$ more than the modified sand.This shows the tendancy of bentonite to produce an unstable fabric.

5) Eventhough the minimum value of deviator stress was shown by sand containing slag and bentonite, the value was $73 \%$ more than the untreated sand. This may be attributed to the ability of fines to improve the sand particle connections.

6) Among all the additives, xanthan gum showed more deviator stress value.This indicates that xanthan gum incorporated sand shows more resistance to liquefaction. In case of denser mixes, sand containing agar and starpol 136 in combination showed the least value of stress at $200 \mathrm{kPa}$ confining pressure.But this value was $124 \%$ more than the untreated sand, making it suitable for resisting liquefaction.

7) For significant strengthening effect, xanthan gum must be in dried condition as biopolymers are highly sensitive to water. Once it is dried thoroughly,a biopolymer matrix gets developed within the soil, generating very high deviator stress values. 
8) When pore water pressure values were compared, geocell incorporated sand showed the maximum value, even more than the untreated sand. This increased value was due to the higher permeability characteristics of geotextile than sand.This makes geocell inappropriate in resisting liquefaction.

9) While analyzing the strength factor values, it can be seen that slag in combination with bentonite is more effective than bentonite alone, as the ultimate strength of untreated sand was increased to five times initial value and two times initial value at $100 \mathrm{kPa}$ and 200 $\mathrm{kPa}$ cell pressures respectively.

10) It was also seen that xanthan gum was the most efficient in increasing the strength, as it increased the strength of sand to thirteen times its initial value.

11) The decline in undrained shear strength was expressed interms of brittleness index, $\mathrm{I}_{\mathrm{B}}$. The plot of brittleness index vs stabilizing agents show that the values of brittleness index obtained in all cases were less than one, indicating that the modified sands show non brittle behavior. Xanthan gum incorporated sand showed the maximum brittleness index, but it was less than the limit of 1 .

12) Considering all these aspects, xanthan gum can show desirable properties. Being a biopolymer, the appropriate usage of it in soil treatment leads to a more sustainable and environment friendly practices.

\section{REFERENCES}

[1] Dr.R. L.B. Ram , P. R. Akshay, J. Namita, N. Samruddhi,S Rishabh, P. Sarang and B. Sharath, "Behaviour of Plastic Strip Reinforced Blast Furnace Slag under Triaxial Loading Condition," International Advanced Research Journal in Science, Engineering and Technology, vol. 5, no. 2,pp. 29- 35, February 2018

[2] K. A. Mohamed ,M. N. Abdelazim and A. E. S. Mostafa, "Evaluating the physical characteristics of biopolymer/soil mixtures,"Arabian Journal of Geosciences, vol.9, no.5, April 2016.

[3] K. Mahdi, C. Amin, N. Hamid and S. S. Ayad, "Effect of flyash on liquefaction behaviour of sand-bentonite mixture,"Soils and Foundations,vol.58,no.5, pp. 1288-1296,October 2018.

[4] K. Mahdi, C. Amin, Y. Yuksel and N. Hamid, "Effect of Lime Treatment on Static Liquefaction Behavior of Sand-Bentonite Mixture,"Journal of Materials in Civil Engineering, vol. 30, no. 11, pp. 06018017: 1-7, November 2018.

[5] L. Dharmesh, N. Sankar and S. Chandrakaran, "Triaxial test on saturated sands reinforced with coir products", International Journal of Geotechnical Engineering, June 2017.

[6] L. Sojeong, I. Jooyoung, C. C. Gye and C. Ilhan, "Laboratory triaxial test behavior of xanthan gum biopolymer-treated sand," Geomechanics and Engineering, vol. 17, no. 5 , pp. 445-452, February 2019.

[7] M. Hasanlourad, S. M. H. Khatami and M. M. Ahmadi, "Effect of Bentonite fine Content on the Triaxial Shear Behavior of Sandy Soils,"AUT Journal of Civil Engineering,vol. 2, no. 2, pp. 177182,August 2018.

[8] N. R. Malidarreh, I. Shooshpasha, S. M. Mirhosseini and M. Dehestani, "Effects of reinforcement on mechanical behaviour of cement treated sand using direct shear and triaxial tests," International Journal of Geotechnical Engineering, March 2017.

[9] R.K. Hamid and C.O.K.Brendan, "Improving Mechanical Properties of Sand Using Biopolymers," Journal of Geotechnical and Geoenvironmental Engineering,vol.139, no.8, pp.1402 - 1406, August 2013.

[10] S. Kwestan and G. Mahmoud , "Soil reinforcement and slope stabilisation using recycled waste plastic sheets," Geomechanics and Geoengineering , October 2019.

[11] S. S. Ayad , C. Amin and N. Hamid, "Experimental Investigation on the Shear Strength Parameters of Sand-Slag Mixtures," International Journal of Geotechnical and Geological Engineering, vol. 11, no.3,pp. 222-227, 2017.

[12] S. S. Ayad , C. Amin and N. Hamid, "Static liquefaction of very loose sand-slag-bentonite mixtures," Soils and Foundations, vol.57, no.3 ,pp.341-356,June 2017.

[13] S. Smitha, K. Rangaswamy and D. S. Keerthi, "Triaxial test behaviour of silty sands treated with agar biopolymer," InternationalJournal of Geotechnical Engineering,October 2019.

[14] W. Yixian ,G. Panpan , L. Xian, L. Hang , L. Yan and Y. Haiping, "Behavior of Fiber-Reinforced and Lime-Stabilized Clayey Soil in Triaxial Tests," Applied Sciences, vol.9, no.5,March 2019. 